\title{
Analysis of Taoist Belief of Compliance with Courtesy from Taoist Philosophy
}

\author{
Xin Dong \\ School of History \\ Nanjing University \\ Nanjing, China 210093
}

\begin{abstract}
China's Taoist philosophy takes Lao Tzu as the founder, and Zhuangzi as the comprehensive representative to absorb different opinions from others; Taoist philosophy has rich content and is one of the important sources of ideological and cultural development in China. Taoism inherited and carried forward the Taoist philosophy, Taoism has always been the core idea and the highest pursuit of Taoist philosophy. Taoist thought is an important source of Taoism, and the Taoist characters Lao Tzu and Zhuangzi have deep impact on Taoism. This paper discusses the origin and development of Taoism, describes the important thought of Taoist philosophy, and further researches the influence of Taoist philosophical thought on Taoism.
\end{abstract}

Keywords-Taoist philosophical thought; Taoist belief; discussion and research

\section{INTRODUCTION}

Taoism is one of the important schools in the history of pre-Qin to Western Han Dynasty, Lao Tzu and Zhuangzi are the main representative of Taoist philosophy and thought. Taoism is the native religion of China, with distinctive Chinese characteristics, having an important position among the Chinese five major religions. Taoist philosophy puts forward the theory of rebirth and noble birth, and provides a set of cultural method based on the theory. Taoism pursues the ultimate purpose and the highest faith of longevity and immortality, and it applies the theory of immortal body to persuade people to keep in good health and cultivate themselves for immortality. Taoist development has an inseparable relationship with Taoism, the role of Taoist philosophy can not be ignored in the transformation and development of Taoism, the interpretation of Taoism on the Taoist philosophy is reflected in the interaction between them two. The core of Taoist thought is Taoism, Taoism inherited and renovated Taoist philosophy, Taoism takes "Tao" as the core and the highest faith. Taoist founder Lao Tzu is revered as the very high lord, and Taoist important books "Tao Te Ching" and "Zhuangzi" are worshipped as "Scriptures" of Taoism.

\section{The ORIGIN AND DeVelopment Of TAOIST Thought}

Taoism is one of the most important schools of thought in the period of the Spring and Autumn and Warring States. In the Western Han Dynasty, the Han emperors, Wen and Jing governed the country by used of Taoist thought, so that the people got rid of the harsh rule of Qin Dynasty. The rulers in the Han dynasty learned from the lessons of the demise of the Qin dynasty, and after getting the regime, they adopted the economic strategy of "make people relaxed and develop production". The theory of the strategy is developed based on the theory of Huang Lao that advocated by Taoists. The theory of Huang Lao made the Yellow Emperor in the legend matched with Lao Tzu each other, together known as the founder of the Taoist. It also proposed a series of Taoist thought such as discarding all desires and worries from the mind, and sitting still as a form of therapy for health. After that, the Han Emperor $\mathrm{Wu}$ accepted Dong Zhongshu's proposal to carry out the strategy of "rejecting the other schools of thought and respecting only confucianism". The Taoist thought had been not accepted by the government from them, but it always has an important role in the reform of ancient thought. In this period, the majority of the schools had an impact and gradually lost their independent position, and only Taoist made a tenacious survival in the troubled times. The metaphysics in the Wei and Jin Dynasties and the Idealistic Philosophy of the Song and Ming Dynasties are developed both based on the absorption of Taoist thought. The development of Buddhism in China is also more or less influenced by the Taoist thought. The Taoist thought is not ranked before Confucianism nor has as many disciples as that of Confucianism and Mohism, but Taoist thought has a unique perception for universe and life, and has a long lasting value and vitality in the philosophical thought.

\section{The PhILOSOPHICAL CORE OF TAOIST Thought}

\section{A. "Tao" Is the Core of Taoist Philosophical Though}

It is roughly divided into three different aspects; one is called Tao of the origin. As the origin of all things in the world, Tao outlines all things in the world as the basic materials; the second is called Tao of principle, that is, as the natural order and inevitability, Tao have a certain objective laws and regulations; the third is called Tao of inaction, that is, Tao has the characteristics of natural inaction.

\section{B. The Main Content of Taoist Philosophy Is Dialectical Wisdom and Methodology}

Lao Tzu proposed that Tao is the origin of all things in the universe, and also the law of change for all things in the 
universe. The principle refers to Lao Tzu's "mildness rather than violence", of which the violence refers to the law of change for of all things in the world, and it is roughly divided into three levels of meaning: (1) Lao Tzu thinks that there is a opposite and complementary relationship among all things and phenomena in the world, that is, all the things and phenomena including "Tao" consist of their two opposite and contradictory sides, for example, there is beauty there will be ugliness; there is kind there will be evil. Lao Tzu puts forward " If everyone knows what is beautiful, relatively knows what is ugly; if knows what is good, relatively knows what is evil", which is just the truth. (2) The theory of opposite and mutual transformation. Lao Tzu pointed out that if the movement of things reaches the maximum limit, it will transform to the opposite, especially the strong things change to the opposite side, which all the actual performance of "mildness rather than violence". (3) Cycle and repeat. The movement of Tao is always cyclic and repeated, just like flowers grow from the root and finally return to the root; waves are combined by water and finally return to the water. Lao Tzu thinks that the cycle and repeat is a most natural law, and also the principle that all things in the world always comply with; human beings are so and all things in nature are the same. The Lao Tzu's saying of "Danger is the next neighbor to security" means the weal and woe are changeable, which is a truth of unpredictable. The next thing is about the relativity. Taoist scholar Chuang Tzu made further deduction based on the Lao Tzu's dialectics, to negate the wrong regularity and differences and find the thinking of relativity. Chuang Tzu once used a story of a Song man who got to the south to sell clothing, to tell us that everything has the relativity of usefulness and uselessness.

\section{Mystery and Relativity in Cognition Are the Most Prominent Feature of Taoist Theory}

Whatever the experiences are, the final result of cognition is to get the understanding of and grasp the Taoism, which is called Taoism access. When narrating Taoism, Lao Tzu raised concepts of in-position viewing and thorough examination, which were used to understand Taoism. The in-position viewing means human souls originally are carries of peace and emptiness, however, seduced by selfish desires and distracting thought, they must be cultured so as to restore the souls. The thorough examination means that all desires and distracting thoughts must be cleared, and culture souls like mirrors without flaws. The concepts raised by Lao Tzu considered the internal limitation of perceptual knowledge and relativity of rational knowledge, hoping to surpass the two to explore high level cognition. Based on epistemology, Chuang Tzu raised concepts as purifying hearts and sitting oblivion, which to a large degree inherited mysticism spirit of Lao Tzu, from grasping of relativity in difference of things, then deny the prescription and difference of things so as to access the relativism. Through exploring the vivid and interesting statements of Chuang Tzu, we can draw a conclusion that Chuang Tzu had wisdom of his own to understand human, which brought use deeper thought and enlightenment.

\section{Differing from Previous Social Outlook, Lao Tzu Had Unique Characteristics, Raising the Theory of Governing by Non-Interference and A Small Country with Few Population}

Advocating the nature and making no interference are called thoughts of sage, the life philosophy of Lao Tzu was to pursue absolute freedom in spirit. Ideal personality, as a sign of life philosophy, is an image to guarantee human value and achieve life goals. In the opinion of Lao Tzu, those who act without interference, experience without abstraction or wear coarse clothes yet with jade heart are called sage; Chuang Tzu called those who get of seven emotions and six sensory pleasures and are beyond life and death sage.

\section{TAOIST THOUGHTS AND TAOISM BELIEFS}

\section{A. Taoist Belief}

The formation of Taoism is a relatively slow process, and the most representative event of Taoism was Scripture of the Great Peace and Five Dou Grain Taoism. Taoism is a religious system inherent in China, which has witnessed the development of more than 1,800 years. Taoism, different from other denominations was rooted and originated in the country. Taoism has unique characteristics, deeply rooted in native soils and deeply influencing Chinese culture to some degree. Taoism is the highest faith, which respects Lao Tzu as hierarch, and the works Tao Te Ching written by Lao Tzu was used as the classic to pursue longevity and immortal. When Taoism was founded, the Tao Te Ching was taken as main works where Tao and moral were taken as basic pursuit, the Tao in Taoism was thought as the origin of all things, from which everything was evolved.

For a long time, most think that Taoism originated from Taoist thought, actually it is an one-sided view. What Taoism advocates is immortal, the highest faith, Taoism thinks that all things including human originate from Taoism. It is recorded in Tao Te Ching that "I am abstracted from the world, the world from nature, nature from the way, and the way from what is beneath abstraction.", it means that Tao is state that has been existing in the universe before all things are created, which is the source of all things, beyond God and the lord of heaven, as a base for the survival and development of all things in universe, Tao is the root for all things to survive. As the mother of all things in the universe, Tao never shows its greatness and strength, yet there is nothing which can dominate Tao in the universe. Taoism makes full use of the "Taoist produces everything", where Tao is seen as directive that cannot go against, and everything goes well if following Tao, otherwise, it will die. In the opinion of Taoism, all things in the world must undergo the course that is birth, growth, recession and death, and only the Taoism is eternal. Lao Tzu ever said, Tao will never die, which will last forever. Chuang Tzu also thought that Tao has been lasting since ancient times. The Taoist thought provides powerful theoretical support to Taoism, whose followers just follow the concept, holding the opinion that only Taoism is eternal, if wanting to be immortal, you must be integrated to Taoism. Taoism has a development method called Shouyi (concentration) method, the concentration just refers to Taoism, and the Taoist followers 
firmly believe that to insist on the Tao can make them immortal and keep the spirits lasting permanently. The foundation and development of different denominations of Taoism may different tenet, yet all take Tao as the highest belief and conduct deep researches on Tao from philosophy, which are not to explore the source of the universe, instead, their purposes tend to pursue theories of immortality. According to the Taoism, the life of human being is not controlled by the universe, and human can predominate it. The followers who develop Tao carefully and permanently will become immortal.

\section{B. Tao of Taoists and Taoism}

Taoist classic works Tao Te Ching states the core thought of Taoism, and its followers take Tao as the highest faith. Taoist thought values individual life, so Taoist philosophy is called life philosophy. The life value described by Taoists has obvious characteristics, thinking that life is a base, and the eternal circle of birth and death shall be treated with an attitude natural and non-interference, and Tao can be beyond life value after development. Taoist life value was raised by Lao Tzu, which had collective embodiment of pursuit of Tao. The Tao stated in Lao Tzu's philosophy thought can be looked as Tao for life, and the pursuit of Lao Tzu was also a reflection of life worship. Based on it, Lao Tzu raised thoughts of "cherish life and value life", Lao Tzu claimed that everything shall follow the nature, rejecting artificial life, which was said a harm to life. Lao Tzu quite cherished the state of life, thinking that the state of life should be tender, and to keep tender can keep life. Besides, Lao Tzu raised the thought of "preserve health", and the life can be preserved through continuous acquisition of energy for life. Lao Tzu also pursued long life, raising a theory of long life.

Taoism successors after Lao Tzu also carried out the concept of life orientated. Chuang Tzu defined the value orientation of "cherish life", creating a set of method of spiritual development, and his thought of "cherish life" was mainly embodied in thoughts such as body protection, long life and natural death. Chuang Tzu thought that everyone in the world has natural life limit, only he or she reaches the life limit, can it meets the natural rules. Chuang Tzu put forward in his works Health Lord: "Everyone who goes with blood and pulse, without pursuit, persistence or harm to spirits can protect his life, nature and spirit till the normal death". Besides, Chuang Tzu also raised use of uselessness and rejection of self opinions to follow the nature in order for a long life. With the methods used, followers can reach the realm advocated by Taoism beyond life and death with spirits lasting permanently. Taoism directly denied death, which pursues immortality, and the creed of Taoism advocates "cherish life and make life happy".

It was recorded in the Tao Te Ching that "the way is limitless, so nature is limitless, so the world is limitless, and so the king is limitless", Taoism changed replaced "the king is limitless" with "the life is limitless", thinking that life is more important than king, which raised the life to a high level of Taoism. Since Taoism values "cherish life and make life happy", so it has been pursuing methods for long life, Taoism improved the method of Taoist life development, forming a unique life development method of its own. Taoists and Taoism has been taking Tao is the highest belief of its philosophy thought and region, thinking that Tao is the beginning of the world and a place for all things to survive and return, Taoist thoughts and Taoism Life Development also described their unceasing pursuit of Tao. Lao Tzu raised "the way bears sensation, sensation bears memory, sensation and memory bear abstraction, and abstraction bears all the world", thinking that Tao was the origin of life, then creating a development method of "emptiness and inaction". Chuang Tzu fully inherited and developed Lao Tzu's thought "Tao is the source of life", pointing out Tao was the base of everything in the world. Chuang Tzu pointed out in his works Master that Tao is the base for the world birth, then stating reasons for Tao to produce the world. Taoism takes Taoist theories as philosophy basis for itself, taking Tao in Tao philosophy thought as the core and the highest pursuit of creed of its own. Taoism thought that Tao is the origin for everything to change, which is permanent. Based on the pursuit of Tao and rules given by Tao, Taosim develops life in order to become immortal.

\section{RELEVANCE BetWeEn PhILOSOPHICAL ThOUght OF TAOIST SCHOOL AND TAOISM BELIEF}

Taoism inherits and carries forward Taoist thought. Although differences exist between the two, they are related. The influence of Taoist thought on Taoism cannot be neglected. Taoism inherits Taoist school in varies aspects. Some scholars observe no so many differences exist between Taoist school and Taoism and they have the same ancient religious origin. The opinion is inherited by western scholars. French Kaltenmark observes "Taoist school and Taoism have the same religious origin and close relationship. Although they have obvious differences, it fails to let people feel they represent different thoughts. We always think Taoism carries forward and continues Taoist thought. Many Chinese scholars also publish relevant discussion. For example, Mou Zhongjian proposes: the religious philosophy of Taoism consists of thoughts of Lao Tzu and Chuang Tzu. Fundamentally, theory of Taoism doesn't separate from Taoist thoughts of Lao Tzu and Chuang Tzu. Taoist school and Taoism have many similarities in pursuing realm of life. For example, universe is regarded as the origin of all things in Taoism. Taoism proposes the origin of the universe is "Tao", "Qi" and "Yi", which produce all things in the world. These things finally point to Tao. As the origin of universe, Tao is also the rule for universe and people's activities. Because the theory of Taoism never separates from Taoist thought, Lao Tzu is regarded as the founder of it. Since the establishment of Taoism theory, the development of Taoism has followed it. The origin of all things and supreme existence are treated as ideological system of Taoism. It indicates the intercommunity between Taoism and Taoist school and the connection between theories.

The relations between philosophical thought of Taoism and Taoism belief include complementation, contrary and multiple connotations. First is the complementary relation. An American scholar once said "It is high-flying to think Taoism is the product of degeneration of Taoist thought as pure philosophy. We should hold different attitudes toward the 
relation between them." Taoist thought has elements that Taoist school doesn't have. These elements have influences on people. For example, Taoist school relates psychology and reason but Taoism relates people's emotions. We must find differences between them and clarify the complementarity of them. Second is the contrary relation. Many contrary aspects exist between thought of Taoism school and Taoism thought; Taoism belief and philosophical thought of Taoist school are different even contrary. Taoist school lets nature take its course while Taoism guides people to go against the law of nature. The third is the relation with multiple connotations. It means Taoism thought combines different schools. Scholars once said: Taoism relates to believers of immortals, the theories of Yin-Yang School and Lao Tzu. Most of people observe Taoism depends on philosophical thought of Taoist school but it's completely wrong according to the above analysis. Some scholar once said, "Thoughts of Lao Tzu and Chuang Tzu only represent Taoism thought and have little relationship with Taoism that develops afterwards. Taoism thought origins from other religion and uses metaphysics of Taoist school."

\section{CONCLUSION}

The relation between Taoist school and Taoism has been discussed by the academic circle. The origins of Taoism thought are complicated, from the perspective of facing death, including the thought on immortality of necromancers in the areas of Yan and Qi, Yin-Yang and five elements, and learning about the Emperor Huang and Lao Tzu, which provide basis for rising and development of Taoism. The center of thought of Taoist school is Tao, which is regarded as the origin of all things and can dominate all things. Origin and development of philosophical thought of Taoist school lay foundation for Taoism belief. The belief of following Tao and valuing etiquette and the philosophical thought of Taoist school enhance each other's beauty and become important parts of Chinese culture foundation and have profound and continuous influence on later generations.

\section{REFERENCES}

[1] Liang Huicheng. Deviation and Regression of Philosophical Thought of Taoist School-From Metaphysics of Wei and Jin Dynasties to Duplicate Metaphysics [J], Journal of Chongqing Radio and TV University, 2014, 26(1): 44-50

[2] Wang Yabing. Conflict and Integration-Manifestation of Philosophical Thoughts of Confucianism and Taoism in Music Is Irrelevant to Grief or Joy [J], Hundred Schools in Arts, 2012, (z2): 341-342, 370

[3] Zhang Shiyang. Taoism Music Artistic Conception of Sikong Tu's Twenty-four Poetic Qualities and Dissemination of Ideas [J], the New Voice of Yue-fu, 2013, 31(2): 78-83

[4] Rigzin Laqing Wangmo. Construction of Lao Tzu's "Tao" SystemAnalysis on Frame of Lao Tzu's Philosophical Thought [J], Theory Research, 2013, (26): 41-42, 121

[5] Liu Ying, Sun Mingzhe, Li Qun. Thinking on Management Art under Chuang Tzu's Philosophical Thought [J], Lantai World, 2014, (6): 127128

[6] Zhang Shu, Zhu Bifa. Modern Survey of "Harmony" Thought in Taoist School [J], Journal of Qujing Normal University, 2013, 32(5):88-90

[7] Zhao Yanfeng. Differences of Philosophical Thoughts of Chuang Tzu and Hui Shi [J], Academic Journal of Zhongzhou, 2011, (3):166-168
[8] Chen Hongbing. Discussion on Ecological Thought of Philosophy of Taoist School [J], Journal of Shangqiu Teachers College, 2012,28(8):69

[9] Ji Liling. Analysis on Ecological Thought of Philosophy of Taoist School [J], Theory Research, 2012, (7):51-52 